\title{
Temperatura base inferior e estacionalidade de produção de genótipos diplóides e tetraplóides de azevém
}

\author{
Lower base temperature and seasonal production of diploid and tetraploid ryegrass genotypes
}

\author{
Liziany MüllerI Paulo Augusto Manfron ${ }^{\text {II }}$ Sandro Luís Petter Medeiros ${ }^{\text {II }}$ \\ Nereu Augusto Streck ${ }^{\text {II }}$ Andréa Mittelmman" ${ }^{\text {III }}$ Durval Dourado Neto ${ }^{\text {IV }}$ \\ Andriéli Hedlund Bandeira" ${ }^{\text {II }}$ Katiule Pereira Morais ${ }^{\text {II }}$
}

\section{RESUMO}

O trabalho tem por objetivo estimar a temperatura base (Tb) para três genótipos diplóides (Comum, Fepagro São Gabriel e LE 284) e dois tetraplóides (Avance e INIA Titán) de azevém. Com os valores de Tb, o trabalho também permitiu investigar se esses genótipos podem apresentar estacionalidade de produção, auxiliando no planejamento alimentar dos rebanhos. Foram realizadas cinco datas de semeadura (11/05, 07/06, 05/07, 09/08 e 01/09/2007) em Santa Maria, Rio Grande do Sul (RS). Os métodos utilizados para cálculo de $\mathrm{Tb}$ foram o da menor variabilidade ou desvio padrão $e$ do desenvolvimento relativo ou equação de regressão. Os valores de Tb, para os genótipos diplóides, variam entre 7,0 e $8,5^{\circ} \mathrm{C}$, já os valores para os tetraplóides variam de 9,0 a $10,6^{\circ} \mathrm{C}$, dependendo do método de estimativa da Tb. As pastagens de azevém com germoplasma diplóide não possuem risco de estacionalidade de produção, mas os tetraplóides, com destaque para o Avance, poderão ter seu crescimento e desenvolvimento reduzidos nos meses de junho a agosto, em Santa Maria, em função das temperaturas mínimas do ar.

Palavras-chave: crescimento, desenvolvimento, Lolium multiflorum, produtividade, temperatura limiar.

\section{ABSTRACT}

The objective of this study was to estimate lower base temperature $\mathrm{Tb}$ of three diploid (Comum, Fepagro São Gabriel, and LE 284 and two tetraploid (Avance and INIA Titán) ryegrass genotypes. With the estimated $\mathrm{Tb}$, it was also possible to investigate if these genotypes may have seasonal production, which helps in programming herds feeding schedules. Five sowing dates (11/05, 07/06, 05/07, 09/08 e 01/ 09/2007) were performed in Santa Maria, RS, Brazil. Two methods were used to estimate Tb: least deviation method and relative development method. Tb values varied from 7.0 to $8.5^{\circ} \mathrm{C}$ for diploid genotypes and from 9.0 to $10.6^{\circ} \mathrm{C}$ for tetraploid genotypes, depending upon the method. Diploid ryegrass germoplasm have no risk of seasonal decrease in forage production, whereas tetraploids, mainly Avance, may have their growth and development decreased from June to August in Santa Maria because of minimum air temperature.

Key words: growth, development, Lolim multiflorum, productivity, threshold temperature.

\section{INTRODUÇÃO}

Para explicar o crescimento e o desenvolvimento de plantas forrageiras, em muitos trabalhos, têm sido quantificadas variáveis morfogênicas, tais como filocrono, taxas de alongamento foliar e de aparecimento de folhas e tempo de vida das folhas. Segundo SANTOS et al. (2004), o uso dessas variáveis é fundamental para nortear práticas de manejo da desfolha, além de servir como critério em programas de seleção visando o melhoramento.

Considerando que as plantas não reconhecem o tempo medido por meio de descritores

\footnotetext{
IPrograma de Pós-graduação em Agronomia, Universidade Federal de Santa Maria (UFSM), Santa Maria, RS, Brasil. E-mail: lizianym@hotmail.com. Autor para correspondência.

IIDepartamento de Fitotecnia, Centro de Ciências Rurais (CCR), UFSM. Av. Roraima, 1000, Campus Universitário, Camobi, 97105-900, Santa Maria, RS, Brasil.

IIIEmbrapa Clima Temperado, Pelotas, RS, Brasil.

${ }^{\text {IV }}$ Departamento de Produção Vegetal, Universidade de São Paulo (USP), Piracicaba, SP, Brasil.
} 
determinados pelo homem (horas, dias, meses) e sim um calendário biológico governado pela temperatura do ambiente, geralmente, utiliza-se como descritor de tempo das variáveis morfogênicas o conceito de tempo térmico, com unidade ${ }^{\circ} \mathrm{C}$ dia ou graus-dia. Os graus-dia são baseados no acúmulo térmico diário dentro dos limites nos quais a planta se desenvolve, definidos pelas temperaturas base inferior e superior (LOZADA \&ANGELOCCI, 1999; PRELA\& RIBEIRO, 2002).

A temperatura base superior geralmente é elevada e raramente atingida a campo durante o ciclo de desenvolvimento das culturas. Assim, de maneira geral, não se considera a temperatura base superior e utiliza-se somente a temperatura base inferior (LOZADA \&ANGELOCCI, 1999; MENDONÇA\& RASSINI, 2006). A temperatura base inferior ( $\mathrm{Tb}$ ) pode ser interpretada como a temperatura abaixo da qual a planta não se desenvolve e, se o fizer, é a uma taxa muito reduzida, que pode ser desprezada (BURIOL et al., 1978). Ela representa o valor de temperatura mínima que limita o acúmulo de matéria seca de uma espécie, de forma que este se torne nulo ou desprezível (McWILLIAM, 1978; SENTELHAS et al., 1994).

Embora o azevém seja uma poácea de ampla utilização no Rio Grande do Sul, visto que proporciona uma elevada produtividade de matéria seca de alta qualidade bromatológica, refletindo em bons índices zootécnicos, não foi encontrada, na literatura, nenhuma referencia sobre sua $\mathrm{Tb}$.

Em muitos trabalhos com produção de forragem, os autores não relatam qual a temperatura base inferior foi adotada (PONTES et al., 2003; SANTOS et al. 2004; CAUDURO et al., 2006), enquanto outros autores (PIGATTO, 2001; GOLÇALVES \& QUADROS, 2003; QUADROS et al., 2005;) adotam valores de crescimento de espécies de estação fria em geral, como a Tb de $5^{\circ} \mathrm{C}$ proposta por COOPER \& TAINTON (1968), e ainda há outros autores, como VIÉGAS (1998), que adotam a Tb do trigo, que é de $0^{\circ} \mathrm{C}$ (FRANK \& BAUER, 1995).

Devido à inexistência da Tb para o azevém e seus genótipos, principalmente daqueles que possuem germoplasmas diferentes (diplóides e tetraplóides), o trabalho teve por objetivo estimar a Tb de cinco genótipos de azevém, durante o período vegetativo. Além disso, de posse dos valores de $\mathrm{Tb}$, o trabalho também permitiu investigar se esses genótipos poderão ser suscetíveis à estacionalidade de produção.

\section{MATERIAL E MÉTODOS}

O experimento foi realizado no Departamento de Fitotecnia da Universidade Federal de Santa Maria, Santa Maria, situada na Depressão Central do Rio
Grande do Sul (RS), com altitude de $95 \mathrm{~m}$, com coordenadas de $29^{\circ} 43^{\prime} \mathrm{S}$ e $53^{\circ} 43^{\prime} \mathrm{W}$. O solo do local é uma transição entre a Unidade de Mapeamento São Pedro (Argissolo Vermelho Distrófico Arênico) e a Unidade de Mapeamento Santa Maria (Alissolo Hipocrômico Argilúvico Típico) (EMBRAPA, 1999). O clima da região é o Cfa (subtropical úmido com verões quentes e sem estação seca definida), conforme classificação de Köppen (MORENO, 1961).

Foram usados cinco genótipos de azevém cultivados em cinco épocas de semeadura, durante o ano agrícola de 2007. O delineamento experimental adotado foi o de blocos ao acaso, com tratamentos distribuídos em esquema fatorial (5x5), com cinco genótipos e cinco épocas de semeadura, com quatro blocos. Os genótipos de azevém utilizados foram três diplóides (Comum, Fepagro São Gabriel e, LE 284) e dois tetraplóides (Avance e INIA Titán). As datas de semeadura foram: 11/05, 07/06, 05/07, 09/08 e 01/09/ 2007.

A correção do pH e a adubação do solo foram realizadas a partir de análise de solo da área experimental, seguindo as recomendações da Comissão de Química e Fertilidade do Solo - RS/SC (2004). Em 15/ 02/07, foram aplicados 3,7t ha ${ }^{-1}$ de calcário (PRNT $75,4 \%)$. Nas semeaduras, foram utilizados $250 \mathrm{~kg} \mathrm{ha}^{-1}$ da formulação 12-32-16(NPK). A adubação nitrogenada em cobertura foi parcelada em três vezes (perfilhamento, alongamento e emborrachamento), com $50 \mathrm{~kg} \mathrm{ha}^{-1} \mathrm{de} \mathrm{N}$, na forma de uréia. O solo foi preparado pelo método convencional, sendo a semeadura feita manualmente em canteiros de $4 \mathrm{~m}^{2}$, que constituíram a unidade experimental, na densidade de $25 \mathrm{~kg} \mathrm{ha}^{-1}$ de sementes, sendo esse valor corrigido de acordo com a pureza e a germinação dos genótipos.

Os dados da temperatura do ar foram obtidos junto à Estação Climatológica Principal da UFSM, pertencente ao $8^{\circ}$ DISME/INMET/MA, localizada a $100 \mathrm{~m}$ da área experimental. A temperatura base e a soma de graus-dia para cada genótipo, no subperíodo vegetativo (emergência - floração), foram estimadas pelo método da menor variabilidade ou pelo método do desvio padrão, conforme ARNOLD (1959), e, por meio do desenvolvimento relativo ou da equação de regressão, segundo BRUNINI et al. (1976) e GBUR et al. (1979).

A estimativa dos graus-dia (GD), em ${ }^{\circ} \mathrm{C}$ dia, acumulados durante um dia, foi obtida pela seguinte fórmula:

Se: $(\mathrm{Tb}=\mathrm{Tmin})$, conforme SCHNEIDER et
al $\mathrm{GD}=(1 / 5)[\mathrm{T} 9 \mathrm{~h}+\mathrm{Tmax}+\mathrm{Tmin}+(2 \mathrm{~T} 21 \mathrm{~h})]-\mathrm{Tb}$
Se: $(\mathrm{Tb}=\mathrm{Tmin})$, conforme VILLA NOVA et al. (1999):

Ciência Rural, v.39, n.5, ago, 2009. 
$\mathrm{GD}=(\mathrm{Tmax}-\mathrm{Tb})^{2} /[2(\mathrm{Tmax}-\mathrm{Tmin})], \mathrm{em}$ que: $\mathrm{GD}=$ graus-dia; T9h e T21h são as temperaturas às $9 \mathrm{~h}$ e $21 \mathrm{~h}$, respectivamente; Tmax e Tmin são as temperaturas máxima e mínima do ar, respectivamente; e Tb é a temperatura base do subperíodo vegetativo.

A soma térmica acumulada (STa), em ${ }^{\circ} \mathrm{C}$ dia, de cada genótipo, foi obtida pelo somatório dos grausdia acumulados durante os dias necessários para completar o subperíodo vegetativo:

$\mathrm{STa}=\mathrm{SGD}$

No método da menor variabilidade, usa-se a premissa de que, numa dada série predeterminada que corresponder ao menor valor do desvio padrão em dias, é considerada a temperatura-base do vegetal em estudo. A expressão utilizada é a seguinte:

$\mathrm{Sd}=(\mathrm{Sdd}) /(\mathrm{T}-\mathrm{Tb})$, em que: $\mathrm{Sd}=$ desvio padrão em dias, para série de experimentos; Sdd= desvio padrão em graus-dia, para toda a série de plantio, para cada valor de temperatura base inferior; $\mathrm{T}=$ temperatura média para toda série de épocas de semeadura sobre a qual sdd é baseada (período experimental); $\mathrm{Tb}=$ temperatura base inferior. Foram usados valores de $\mathrm{Tb}$ de 0 a $15^{\circ} \mathrm{C}$, com intervalos de $0,5^{\circ} \mathrm{C}$.

O método do desenvolvimento relativo (DR) consiste em calcular DR por:

$\mathrm{DR}=\mathrm{a}+\mathrm{b} . \mathrm{T}$, em que: $\mathrm{T}$ é a temperatura média $\left({ }^{\circ} \mathrm{C}\right)$; a e b são os coeficientes linear e angular da regressão linear simples. DR é calculado por:

$\mathrm{DR}=100 / \mathrm{n}$, em que: $\mathrm{DR}=$ desenvolvimento relativo à temperatura média do ar; 100 = valor arbitrário de ponderação; $\mathrm{n}$ = dias do ciclo da cultura (subperíodo vegetativo).

Quando DR for igual à zero, T será igual à Tb; sendo obtida por:

$\mathrm{Tb}=-\mathrm{a} / \mathrm{b}$

Após a determinação da temperatura base inferior de cada genótipo, esses valores foram plotados com os valores de temperatura mínima, máxima e média do ar referentes às Normais Climatológicas obtidas com dados do período de 1961 a 1990, da Estação Climatológica Principal de Santa Maria, RS, pertencente ao $8^{\circ}$ Distrito de Meteorologia do Instituto Nacional de Meteorologia (INMET, 1992).

\section{RESULTADOS E DISCUSSÃO}

A temperatura base inferior ( $\mathrm{Tb}$ ) estimada pelo método de menor variabilidade, para os genótipos de azevém diplóides, variaram de 7,0 a $8,5^{\circ} \mathrm{C}$ e, para os tetraplóides, de 9 a $10,5^{\circ} \mathrm{C}$. Pelo método de desenvolvimento relativo para a $\mathrm{Tb}$ dos diplóides, as temperaturas oscilaram de 7,6 a $8,2^{\circ} \mathrm{C}$ e dos tetraplóides, de 9,7 a $10,6^{\circ} \mathrm{C}$ (Tabela 1). O genótipo Comum apresentou a menor $\mathrm{Tb}$, já o genótipo Avance apresentou a maior.

De maneira geral, a estimativa da $\mathrm{Tb}$, com o método da menor variabilidade, foi semelhante ao método do desenvolvimento relativo para cada genótipo (Tabela 1). Houve uma variação da Tb entre métodos de $0,1 \mathrm{a} 0,7^{\circ} \mathrm{C}$. PEDRO JÚNIOR et al. (2004) também encontraram variações de 0,3 a $0,5^{\circ} \mathrm{C}$ na $\mathrm{Tb}$ estimada por dois métodos, para diferentes genótipos de triticale. Estimando a temperatura base inferior de 19 genótipos de feijão, CARGNELUTTI-FILHO et al. (2005) relataram que encontraram pequenas diferenças entre esses dois métodos, a maioria variando entre 0,2 e $1,8^{\circ} \mathrm{C}$.

O método de desenvolvimento relativo obteve uma boa relação linear entre a taxa de desenvolvimento e a temperatura média, pois seus coeficientes de determinação foram altos, mostrandose adequado para estimar a Tb (Tabela 1 ).

A partir desses resultados, pode-se inferir que, para o azevém, a Tb dos genótipos diplóides é

Tabela 1 - Estimativa da temperatura base inferior por dois métodos (Menor variabilidade e Desenvolvimento relativo) e equações de regressão e coeficiente de determinação $\left(\mathrm{R}^{2}\right)$ pelo método do Desenvolvimento relativo, para cinco genótipos de azevém. UFSM, 2008.

\begin{tabular}{|c|c|c|c|}
\hline \multirow{2}{*}{ Genótipos } & \multicolumn{2}{|c|}{------------------Temperatura base $\left({ }^{\circ} \mathrm{C}\right)$------------------ } & \multirow{2}{*}{ Equação } \\
\hline & Menor variabilidade & Desenvolvimento relativo & \\
\hline \multicolumn{4}{|l|}{ Diplóides } \\
\hline Comum & 7,00 & 7,60 & $\mathrm{Y}=0,121 \mathrm{X}-0,92 * \mathrm{R}^{2}=0,98$ \\
\hline Fepagro São Gabriel & 8,50 & 8,20 & $\mathrm{Y}=0,133 \mathrm{X}-1,09 * \mathrm{R}^{2}=0,95$ \\
\hline LE 284 & 8,00 & 8,10 & $\mathrm{Y}=0,116 \mathrm{X}-0,94 * \mathrm{R}^{2}=0,88$ \\
\hline \multicolumn{4}{|l|}{ Tetraplóides } \\
\hline Avance & 10,50 & 10,60 & $\mathrm{Y}=0,138 \mathrm{X}-1,46^{*} \mathrm{R}^{2}=0,97$ \\
\hline INIA Titán & 9,0 & 9,70 & $\mathrm{Y}=0,101 \mathrm{X}-0,98 * \mathrm{R}^{2}=0,94$ \\
\hline
\end{tabular}

* $(\mathrm{P}<0,05)$ 
inferior à dos tetraplóides. Os resultados obtidos no presente estudo corroboram trabalhos desenvolvidos na Universidade da Flórida, com azevém diplóides e tetraplóides, em que genótipos diplóides foram mais tolerantes ao frio que tetraplóides (BLOUNT et al., 2005).

A temperatura do ar é o principal elemento meteorológico que influencia o desenvolvimento e o crescimento vegetal e uma das melhores maneiras de relacioná-la ao desenvolvimento é por meio do uso do sistema de unidades térmicas ou graus-dia (BRUNINI et al., 1976). A duração do ciclo de desenvolvimento das cultivares de cereais de estação fria, cultivadas no Sul do Brasil, tem-se mostrado variável, principalmente devido à ação da temperatura do ar, uma vez que outros fatores ambientais exercem menor efeito sobre o desempenho agronômico das espécies (MUNDSTOCK, 1983).

Trigos cultivados no Sul do Brasil são pouco afetados pelo fotoperíodo (DEL POZZO et al., 1987; RODRIGUES et al., 2001). No entanto, esses autores relatam que alguns genótipos de trigo são sensíveis ao fotoperíodo; porém, se o comprimento do dia não variar mais que duas horas, haverá uma mínima variação na estimativa da $\mathrm{Tb}$ nesses genótipos e isso seria insuficiente para provocar alterações significativas na Tb. Para o azevém, existe carência na literatura de informações sobre sua sensibilidade ao fotoperíodo. Assim, considerou-se que os métodos utilizados neste estudo são adequados, pois não houve variação maior que duas horas durante o subperíodo vegetativo para os genótipos avaliados.
Os valores de temperatura base inferior encontrados para o azevém neste estudo são superiores aos valores relatados para o trigo, uma espécie pertencente também ao grupo dos cereais de inverno, que é de $4,4^{\circ} \mathrm{C}$ (NUTTONSON, 1955; PETERSON, 1965) e $5^{\circ} \mathrm{C}$, na região Sul do Brasil (MOTA, 1989). SHAYKEWICH (1995) comentou que diferentes valores de temperatura base inferior têm sido usados para o trigo e a cevada, variando entre 0 e $4^{\circ} \mathrm{C}$. Esses resultados indicam que a pressuposição adotada, em muitos trabalhos científicos, de que a Tb do azevém é $5^{\circ} \mathrm{C}$ (COOPER \& TAINTON, 1968) ou $0^{\circ} \mathrm{C}$, em analogia ao trigo (FRANK \& BAUER, 1995), não é apropriada.

Por outro lado, para o triticale, PEDRO JÚNIOR et al. (2004) obtiveram valores de temperatura base inferior entre 8 e $10^{\circ} \mathrm{C}$, dependendo da cultivar, os quais são semelhantes aos atribuídos para o azevém. Segundo esses autores, o triticale é uma planta rústica originalmente utilizada para produzir farinha a ser adicionada ao trigo na panificação, mas hoje seu uso está mais voltado para alimentação animal por apresentar ótimos teores de proteína.

EVERS et al. (1997) relataram que o crescimento do azevém anual nos EUA cessou quando a temperatura média diária foi inferior a $6^{\circ} \mathrm{C}$ e que a temperatura ótima está em torno de $18^{\circ} \mathrm{C}$. Esse valor de temperatura base inferior está um pouco abaixo dos valores observados para os diplóides $\left(7\right.$ a $\left.8,5^{\circ} \mathrm{C}\right)$, neste estudo.

Na análise, considerando-se as Normais Climatológicas mensais de temperatura do ar em Santa Maria, verifica-se que não há risco de estacionalidade da produção de azevém para os genótipos diplóides (Figura 1). Para os genótipos tetraplóides,

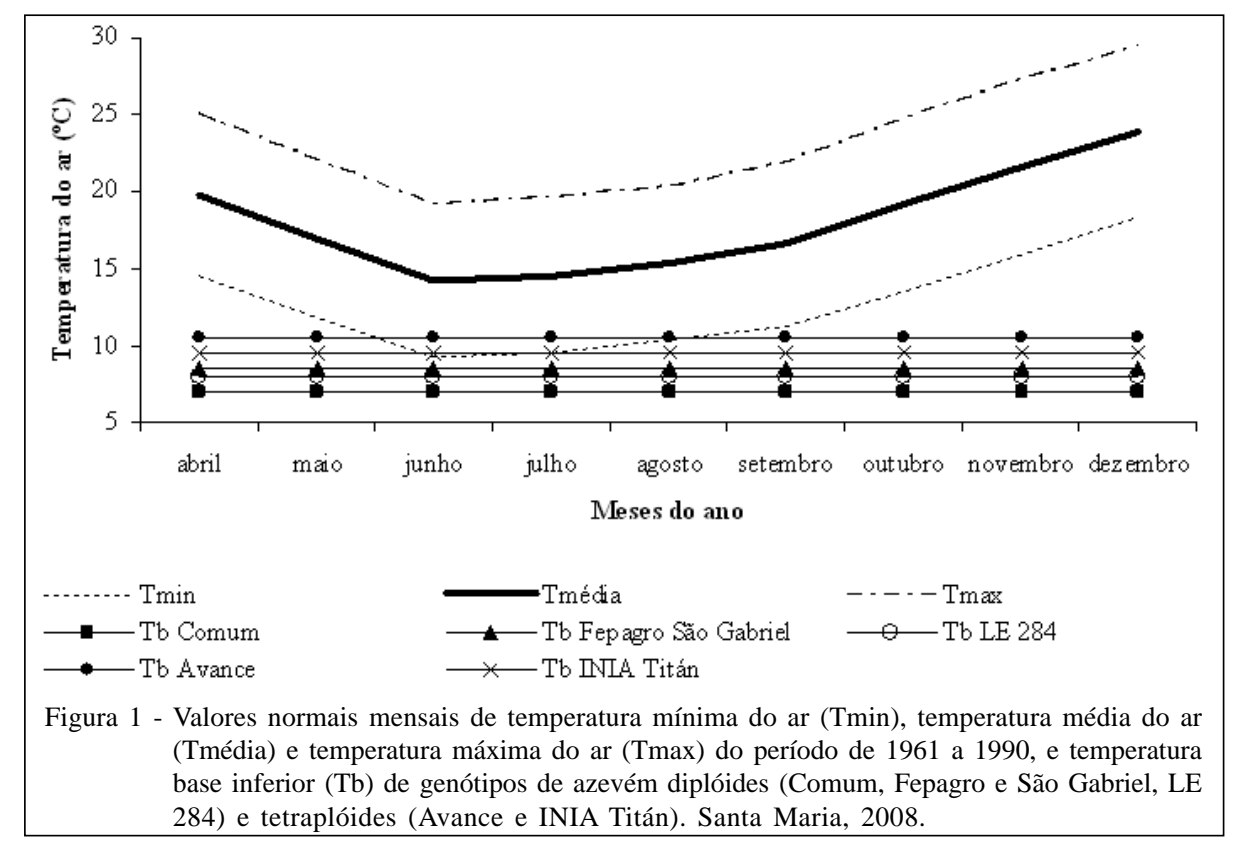

Ciência Rural, v.39, n.5, ago, 2009. 
principalmente o Avance, nos meses de junho, julho e agosto, o crescimento e o desenvolvimento tendem a diminuir em função das temperaturas mínimas do ar estarem abaixo da $\mathrm{Tb}$ desses genótipos, mas a temperatura média do ar é acima da temperatura base inferior.

Como foi observado neste trabalho, existem diferenças entre populações, podendo-se usar a Tb como um critério de melhoramento, a fim de evitar a estacionalidade de produção. Esses resultados também favorecem o azevém como alternativa de forrageira anual de estação fria para superar a estacionalidade de produção apresentada pelas pastagens nativas no Rio Grande do Sul.

\section{CONCLUSÃO}

Os valores de temperatura base inferior estimados para os genótipos de azevém diplóides foram em torno de $7^{\circ} \mathrm{C}$, para Comum, e $8^{\circ} \mathrm{C}$, para São Gabriel e Estanzuela 284, já para os tetraplóides os valores foram de $10,5^{\circ} \mathrm{C}$, para Avance, e $9^{\circ} \mathrm{C}$, para o Titán. Além disso, os genótipos diplóides de azevém estudados não apresentam estacionalidade de produção em relação à temperatura média e à temperatura mínima do ar.

\section{AGRADECIMENTO}

Ao Conselho Nacional de Desenvolvimento Científico e Tecnológico (CNPq), pelas bolsas concedidas aos pesquisadores e aos Professores Cléber José Tonetto e Rosenei Felippe Knackfuss.

\section{REFERENCIAS}

ARNOLD, C.Y. The determination and significance of the base temperature in a linear heat unit system. Journal of the American Society for Horticultural Science, Geneva, v.74, p.430-445, 1959

BLOUNT, A.R. et al. Annual ryegrass. Tampa's: Agronomy Department, Florida Cooperative Extension Service, Institute of Food and Agricultural Sciences, University of Florida, 2005. 5 p.

BRUNINI, O. et al. Temperatura-base para alface cultivar 'White Boston', em um sistema de unidades térmicas. Bragantia, Campinas, v.35, n.19, p.213-219, 1976.

BURIOL, G.A. et al. Temperatura base dos subperíodos emergência-floração e floração maturação de quatro linhagens de lentilha (Lens culinaris medic). Revista Ciência Rural, Santa Maria, v.8, n.2, p.175-184, 1978 .

CARGNELUTTI FILHO, A. et al. Determinação da temperatura base e graus-dia para cultivares de feijão. In: CONGRESSO NACIONAL DE PESQUISA DE FEIJÃO, 8., 2005, Goiânia. Anais... Santo Antônio de Goiás, Goiânia : Embrapa Arroz e Feijão, 2005. V.2, p.1136-1139.
CAUDURO, G.F. et al. Variáveis morfogênicas e estruturais de azevém anual (Lolium multiflorum Lam.) manejado sob diferentes intensidades e métodos de pastejo. Revista Brasileira de Zootecnia, Viçosa, v.35, n.4, pp. 1298-1307, 2006. Disponível em: <http://www.scielo.br/ scielo.php ?script =sci_arttext\&pid=S 1516 35982006000500007\&lng=pt\&nrm=iso>. Doi: 10.1590/ S1516-35982006000500007.

COMISSÃO DE QUÍMICA E FERTILIDADE DO SOLO - RS/ SC. Manual de adubação e calagem para os Estados do Rio Grande do Sul e de Santa Catarina. 10.ed. Porto Alegre: SBCS - Núcleo Regional Sul/UFRGS, 2004. 400p.

COOPER, J.P.; TAINTON, N.M. Light and temperature requirements for the growth of tropical and temperate grasses. Herbage Abstracts, Wallingford, v.38, n.3, p.167-176, 1968.

DEL POZZO, A.H. et al. Relationship of base temperature to development of spring wheat. Experimental Agriculture, Cambridge, v.23, p.21-30, 1987.

EMBRAPA. Sistema brasileiro de classificação de solos. Brasília, 1999. 412p.

EVERS, G.W. et al. Ecology and production of annual ryegrass. In ROUQUETTE, F.M. Jr.; NELSON, L.R. (ed.) Cidade sede?: Ecology, Production, and Management of Lolium for forage in the USA, 1997. p.29-44.

FRANK, A.B.; BAUER, A. Phyllochron differences in wheat, barley and forage grasses. Crop Science, Madison, v.35, n.1, p.19-23, 1995.

GBUR, E.E. et al. Use of segmented regression in determination of the base-temperature in heat accumulation models. Agronomy Journal, Madison, v.71, p.949-953, 1979.

GONÇALVES, E.N.; QUADROS, F.L.F. Características morfogênicas de azevém anual (Lolium multiflorum Lam.) sob pastejo em sistemas intensivos de utilização. Ciência Rural, Santa Maria, v.33, n.6, p.1129-1134, 2003. Disponível em: $<$ http://www.scielo.br/scielo.php?script=sci_arttext\&pid=S0103$84782005000100029 \& \operatorname{lng}=$ en\&nrm=iso $>$. Doi: 10.1590/S010384782005000100029 .

INSTITUTO NACIONAL DE METEOROLOGIA (INMET) Normais climatológicas (1961-1990). Brasília: INMET, 1992. 84p.

LOZADA, B.I.; ANGELOCCI, L.R. Determinação da temperatura-base e de graus-dia para estimativa da duração do subperíodo da semeadura à floração de um híbrido de milho. Revista Brasileira de Agrometeorologia, Santa Maria, RS, v.7, n. 1, p.31-36, 1999.

MENDONÇA, F.C.; RASSINI, J.B. Temperatura-base inferior e estacionalidade de produção de gramíneas forrageiras tropicais. São Carlos: Embrapa Pecuária Sudeste, 2006. (Circular Técnica Embrapa, 45).

McWILLIAM, J.R. Response of pastures plants to temperature. In: WILSON, J.R. (Ed). Plant relation in pastures. East Melbourne, Australia: CSIRO, 1978. p.17-34.

MORENO, J.A. Clima do Rio Grande do Sul. Porto Alegre, Secretaria da Agricultura, 1961. 73p.

Ciência Rural, v.39, n.5, ago, 2009. 
MOTA, F.S. Agrometeorologia do trigo no Brasil. Campinas: Sociedade Brasileira de Agronomia, 1989. 122 p.

MUNDSTOCK, C.M. Cultivo dos cereais de estação fria. Porto Alegre (RS): NBS, 1983. 265p.

NUTTONSON, M.Y. Wheat-climate relationships and use of phenology in ascertaining the thermal and photothermalrequirements of wheat. Washington: American Institute of Crop Ecology, 1955. 388p.

PEDRO JUNIOR, M. J. et al. Temperatura-base, graus-dia e duração do ciclo para cultivares de triticale. Bragantia, Campinas, v.63, n.3, p.447-453, 2004.

PETERSON, R.F. Wheat: botany, cultivation and utilization. World Crops Books. London: Leonard Hill Books, 1965. 421p

PIGATTO, A.G.S. Dinâmica da vegetação e do crescimento de Lolium multiflorum Lam. e Paspalum urvillei Steud., em área de várzea, sob pastejo. 2001. 100f. Dissertação (Mestrado em Zootecnia) - Universidade Federal de Santa Maria.

PRELA, A.P.; RIBEIRO, A.M.A. Determinação de graus-dia acumulados e sua aplicação no planejamento do cultivo de feijãovagem (Phaseolus vulgaris L.) para Londrina - PR. Revista Brasileira de Agrometeorologia, Santa Maria, v.10, n.1, p.83-86, 2002.

PONTES, L.S. et al. Variáveis morfogênicas e estruturais de azevém anual (Lolium multiflorum Lam.) manejado em diferentes alturas. Revista Brasileira de Zootecnia, v.32, n.4, p.814-820, 2003. Disponível em: <http://www.scielo.br/ scielo.php? script =sci_arttext\&pid=S 1516 $35982003000400005 \& \operatorname{lng}=$ en $\&$ nrm $=$ iso $>$. Doi: 10.1590/ S1516-35982003000400005.
QUADROS, F.L.F. et al. Morfogênese de Lolium multiflorum Lam. e Paspalum urvillei steud sob níveis de adubação de fósforo e potássio. Ciência Rural, Santa Maria, v. 35, n. 1, p. 181186. 2005. Disponível em: <http://www.scielo.br/ scielo.php? script = sci_arttext \& pid=S0103$84782005000100029 \& \operatorname{lng}=$ en $^{2} \mathrm{nrm}=\mathrm{iso}>$. Doi: $10.1590 /$ S0103-84782005000100029.

RODRIGUES, O. et al. Desenvolvimento de trigo: efeito da temperatura. Passo Fundo: Embrapa Trigo, 2001. V.03, p.1-8. (Circular Técnica).

SANTOS, R.J. et al. Caracterização morfogênica de acessos de azevém (Lolium multiflorum Lam.). In: REUNIÃO DO GRUPO TÉCNICO EM FORRAGEIRAS DO CONE SUL ZONA CAMPOS, 20., 2004, Salto. Anais... Montevideo: Fac. de Agronomia, 2004. p.8-9.

SCHNEIDER, F.M. et al. Temperatura base e soma térmica do subperíodo semeadura emergência das cultivares de soja. Ciência Rural, Santa Maria, v.17, n.4, p.229-308, 1987.

SHAYKEWICH, C.F. An appraisal of cereal crop phenology modelling. Canadian Journal of Plant Science, Ottawa, v.75, n.2, p.329-341, 1995.

SENTELHAS, P.C. et al. Temperatura-base e graus-dia para cultivares de girassol. Revista Brasileira de Agrometeorologia, Santa Maria, v.2, n.1, p.43-49, 1994.

VIÉGAS, J. Análise do desenvolvimento foliar e ajuste de um modelo de previsão do rendimento potencial de matéria seca de azevém anual (Lolium multiflorum Lam.). 1998. 166f. Tese (Doutorado em Zootecnia) - Universidade Federal do Rio Grande do Sul.

VILLA NOVA, N.A. et al. Modelo para a previsão da produtividade do capim elefante em função de temperatura do ar, fotoperíodo e frequêencia de desfolha. Revista Brasileira de Agrometeorologia, Santa Maria, v.7, n.1, p.75-79, 1999. 